\title{
PERUBAHAN SIFAT FISIK DAN STABILITAS DIMENSI KAYU AKIBAT PENGAWETAN MENGGUNAKAN IMPREGNASI KARBONDIOKSIDA
}

\author{
Changes in the Physical Properties and Dimensional Stability of Preserved Wood Using Carbon Dioxide \\ Impregnation
}

Ifa Zanty Wahyuni, Musrizal Muin, Suhasman

\begin{abstract}
The effect of preservative treatment using carbon dioxide as a carrier solvent on wood physical properties and dimensional stability had been observed on three commercial wood species (Agathis sp., Palaquium $s p$., and Heritiera sp.). For the purpose of the study, wood samples measuring $1,5(\mathrm{R}) \times 1,5(\mathrm{~T}) \times 15(\mathrm{~L}) \mathrm{cm}$ were prepared. Treatment was conducted at elevated temperature $\left(5^{\circ} \mathrm{C}-35^{\circ} \mathrm{C}\right)$ and increased pressure $\left(60-80 \mathrm{kgf} / \mathrm{cm}^{2}\right)$ on one occasion with five replicates using two specimens of each wood species for each treatment. The final treatment condition was maintained for three different periods (10, 20, 30 minutes). Results indicated that the physical properties and dimensional stability of the preserved wood were not significantly affected by the application of $\mathrm{CO}_{2}$ impregnation as carrier solvent.
\end{abstract}

Key words: Preservative treatment, Carbon dioxide, Carrier solvent, Wood physical properties, Wood dimensional stability

\section{PENDAHULUAN}

Peningkatan ketahanan kayu terhadap organisme perusak kayu dan pencegahan kerugian ekonomis yang ditimbulkannya banyak dilakukan dengan usaha pengawetan. Pengawetan kayu pada prinsipnya adalah memasukkan bahan kimia yang bersifat racun ke dalam kayu untuk melindungi kayu dari serangan organisme perusak. Metode pengawetan yang umum digunakan adalah pengawetan metode sederhana atau tanpa tekanan (perendaman, pencelupan, pemulasan, penyemprotan dan pembalutan) dan pengawetan menggunakan tekanan (metode proses sel penuh dan metode proses sel kosong). Metode pengawetan menggunakan tekanan menjadi pilihan dan lebih komersial dibanding metode tanpa tekanan karena keunggulannya dalam memasukkan bahan kimia ke dalam kayu dan menghasilkan kayu-kayu yang awet. Metodemetode tersebut dilakukan dengan menggunakan media pelarut berupa air atau minyak. Penggunaan bahan pelarut ini potensial menimbulkan dampak negatif terhadap lingkungan karena limbah cair yang dihasilkannya. Metode pengawetan tersebut juga dapat menyebabkan perubahan sifat fisik dan mekanis kayu sebagai akibat proses pengeringan ulang dari kayu yang diawetkan. Oleh karena itu, perlu dicari alternatif untuk mengembangkan suatu teknologi pengawetan yang menggunakan bahan pelarut yang tidak membahayakan lingkungan. Salah satu alternatif yang mulai dikembangkan adalah penggunaan $\mathrm{CO}_{2}$ sebagai carrier solvent (pelarut pembawa). Penggunaan $\mathrm{CO}_{2}$ untuk impregnasi bahan pengawet ke dalam kayu diyakini tidak menimbulkan dampak negatif terhadap lingkungan. Hal ini didukung oleh sifat dasar pelarut pembawa tersebut yang berupa gas sehingga tidak menyebabkan adanya tetesantetesan bahan pengawet atau pengeringan ulang setelah pengawetan. Namun demikian, penggunaan $\mathrm{CO}_{2}$ sebagai pelarut pembawa menuntut kondisi tekanan yang tinggi sehingga dikhawatirkan akan mempengaruhi sifat fisik dan dimensi kayu yang diawetkan. Oleh karena itu, penelitian ini dilakukan untuk melihat pengaruh impregnasi $\mathrm{CO}_{2}$ sebagai pelarut pembawa terhadap sifat fisik dan stabilitas dimensi beberapa jenis kayu yang diawetkan.

\section{BAHAN DAN METODE}

\section{Persiapan Sampel Uji}

Sampel uji yang akan digunakan adalah sampel uji bebas cacat dari tiga jenis kayu 
komersil, yaitu kayu agathis (Agathis sp.), kayu nyatoh (Palaquium sp.), dan kayu palapi (Heritiera sp.) dengan ukuran $1,5 \mathrm{~cm}$ (radial) $\times 1,5 \mathrm{~cm}$ (tangensial) $\times 15 \mathrm{~cm}$ (longitudinal). Pada bagian ujung setiap sampel uji diberi "coating" berupa epoxy resin untuk menghindari masuknya bahan pengawet dari arah longitudinal, dimana impregnasi $\mathrm{CO}_{2}$ diharapkan berpenetrasi dari permukaan kayu bukan pada ujungnya sesuai dengan keadaan yang biasa diharapkan dalam proses pengawetan komersial. Seluruh sampel uji kemudian ditandai pada tiga titik dengan jarak yang sama sepanjang sampel uji untuk pengukuran dimensi tebal dan lebarnya. Sebelum diawetkan, sampel uji terlebih dahulu dikondisikan pada suhu $60^{\circ} \mathrm{C}$ selama \pm 48 jam, ditimbang beratnya, kemudian diukur dimensinya dan diperhitungkan sebagai kondisi awal sampel uji.

\section{Persiapan Bahan Pengawet}

Bahan pengawet yang digunakan adalah Silafluofen 95,8 \% (Dainihon Jockugiku Co. Ltd.Japan), suatu termisida non-ester pyrethroid. Bahan pengawet ini telah digunakan secara luas dalam pengawetan kayu karena sifatnya yang stabil pada berbagai kondisi lingkungan pemakaian (Minamite et al., 1990). Bahan pengawet tersebut memiliki nilai racun pada retensi $0,025 \mathrm{~kg} / \mathrm{m}^{3}$ (Muin dan Tsunoda, 2004). Dalam penelitian ini, bahan pengawet tersebut dipersiapkan dengan cara melarutkannya dalam co-solvent ethanol (p.a $99,9 \%$, Merc) dengan konsentrasi $20 \%$. Dalam setiap proses pengawetan, $5 \mathrm{ml}$ larutan pengawet tersebut dimasukkan ke dalam tangki bahan pengawet yang untuk selanjutnya siap diimpregnasikan masuk ke dalam kayu pada saat proses pengawetan dilakukan.

\section{Proses Pengawetan}

Dua sampel uji dari setiap jenis kayu yang telah dipersiapkan dan diukur dimensinya serta ditimbang beratnya dimasukkan ke dalam tangki pengawetan. Setelah itu, $\mathrm{CO}_{2}$ dialirkan dari tabung ke dalam tangki bahan pengawet yang telah diisi dengan $5 \mathrm{ml}$ larutan bahan pengawet dan selanjutnya dialirkan ke dalam tangki pengawetan. Kombinasi suhu $15^{\circ} \mathrm{C}$ dengan tekanan $60 \mathrm{~kg} / \mathrm{cm}^{2}$ digunakan pada tahap awal, kemudian suhu tersebut ditingkatkan secara perlahan-lahan hingga mencapai suhu $35^{\circ} \mathrm{C}$ untuk meningkatkan fase $\mathrm{CO}_{2}$ dari cair menjadi superkritis. Kondisi akhir tersebut dipertahankan selama tiga jangka waktu yang berbeda, yaitu 10, 20, dan 30 menit. Proses pengawetan dilakukan dengan lima (5) kali ulangan, sehingga untuk masing-masing jenis kayu dibutuhkan 10 sampel uji. Proses pengawetan di atas juga dilakukan dengan hanya menggunakan $\mathrm{CO}_{2}$ tanpa bahan pengawet untuk memperoleh angka koreksi atas pengaruh tunggal dari pelarut pembawa tersebut.

\section{Penentuan sifat Fisik dan Stabilitas Dimensi Kayu}

Setelah proses pengawetan, setiap sampel uji dikeluarkan dari tangki pengawetan, diamati keadaan fisiknya, dikondisikan, dan ditimbang beratnya serta diukur kembali dimensinya pada titik/tempat dan dengan cara yang sama seperti sebelum pengawetan. Sifat fisik kayu (kadar air, kerapatan, stabilitas dimensi, dan T/R Rasio) ditentukan berdasarkan data-data hasil pengukuran tersebut.

\section{Analisis Data}

Penelitian ini menggunakan percobaan faktorial dengan rancangan acak lengkap (Gasperz, 1991), dimana setiap kombinasi perlakuan diulang sebanyak 5(lima) kali. Perlakuan terdiri atas 2 faktor, yaitu faktor lama pengawetan $(0,10,20$, dan 30 menit) serta faktor jenis kayu (agathis, nyatoh, dan palapi).

\section{HASIL DAN PEMBAHASAN}

Hasil pengamatan terhadap kayu yang telah diawetkan dalam penelitian ini menunjukkan bahwa proses pengawetan menggunakan $\mathrm{CO}_{2}$ sebagai pelarut pembawa tidak memberikan pengaruh negatif terhadap penampakan kayu. Akan tetapi pada kondisi perlakuan tertentu, penggunaan $\mathrm{CO}_{2}$ tersebut dapat menyebabkan retak dan pecah pada kayu nyatoh. Meskipun demikian, adanya retak dan pecah ini hanya dijumpai pada satu sampel dari sepuluh sampel yang diawetkan dengan kondisi perlakuan 10 menit. Oleh karena itu, keadaan ini dapat saja disebabkan oleh keadaan sampel uji yang memang mudah mengalami keretakan. Hal ini didasarkan pada kenyataan bahwa perlakuan pada kondisi perlakuan dengan proses yang lebih lama, 20 dan 30 menit tidak menyebabkan keretakan pada sampel uji kayu nyatoh lainnya. 
Hasil penelitian ini juga menunjukkan gejala yang berbeda dengan yang dikemukakan oleh Hunt dan Garrat (1953), yaitu bahwa batas untuk menaikkan tekanan pada proses pengawetan tanpa menyebabkan kayu retak atau collapse tergantung pada kekuatan mekanis kayu. Dalam penelitian ini, kayu yang berpotensi mengalami retak dan pecah adalah kayu nyatoh, meskipun kayu tersebut secara mekanis pada dasarnya lebih kuat dari kayu agathis (Martawijaya, dkk., 1981). $\mathrm{Hal}$ ini menunjukkan bahwa proses pengawetan menggunakan $\mathrm{CO}_{2}$ sebagai pelarut memiliki karakteristik dan pengaruh yang berbeda bila dibanding dengan menggunakan pelarut cair. Dalam hal ini, penelitian-penelitian interaksi fisik yang terjadi selama proses pengawetan tersebut sangat diperlukan.

Hasil pengamatan terhadap kadar air kesetimbangan, kerapatan, penyusutan/ pengembangan arah tangensial dan arah radial $T / R$ rasio dari sampel uji sebelum dan setelah pengawetan dapat bervariasi pada setiap jenis kayu dan perlakuan seperti diuraikan dalam bagian-bagian berikut:

\section{Kadar Air Kesetimbangan}

Hasil pengamatan terhadap kadar air kesetimbangan pada kayu agathis, nyatoh, dan palapi yang melalui proses pengawetan dan tanpa melalui proses pengawetan yang diamati pada keadaan suhu rata-rata $31^{\circ} \mathrm{C}$ dan kelembaban rata-rata $69 \%$ menunjukkan bahwa rata-rata kadar air kesetimbangan kayu agathis lebih tinggi dari kayu nyatoh dan kayu palapi yaitu sebesar $13,88 \%$ sedangkan kayu nyatoh dan kayu palapi masingmasing sebesar $13,12 \%$ dan $13,34 \%$. Hasil analisis ragam menunjukkan bahwa kadar air kesetimbangan kayu tidak dipengaruhi secara nyata oleh proses pengawetan. Kadar air kesetimbangan kayu agathis, nyatoh, dan palapi sebelum dan setelah mengalami proses pengawetan dapat dilihat pada Tabel 1.

\section{Kerapatan Kayu}

Hasil pengamatan terhadap kerapatan kayu agathis, kayu nyatoh, dan kayu palapi yang melalui proses pengawetan dan tanpa melalui proses pengawetan menunjukkan bahwa kayu palapi memiliki rata-rata kerapatan kayu lebih tinggi dari kayu nyatoh dan kayu agathis yaitu sebesar 0,60 $\mathrm{g} / \mathrm{cm}^{3}$, sedangkan kayu nyatoh dan kayu agathis masing-masing sebesar $0,45 \mathrm{~g} / \mathrm{cm}^{3}$ dan 0,51 $\mathrm{g} / \mathrm{cm}^{3}$. Hasil analisis ragam juga menunjukkan bahwa proses pengawetan termasuk lamanya tidak berpengaruh nyata terhadap kerapatan kayu. Kerapatan kayu agathis, nyatoh, dan palapi sebelum dan setelah mengalami proses pengawetan dapat dilihat pada Tabel 2.

Table 1. Equilibrium moisture content of wood before and after preservative treatment using carbon dioxide impregnation

\begin{tabular}{lcccc}
\hline \multirow{2}{*}{ Wood species } & \multicolumn{4}{c}{ Equilibrium moisture content (\%) } \\
\cline { 2 - 5 } & Before treatment & \multicolumn{3}{c}{ After treatment } \\
\cline { 2 - 5 } & & 10 min. & 20 min. & 30 min. \\
\hline Agathis sp. & 14,26 & 13,80 & 13,65 & 13,82 \\
Palaquium sp. & 12,90 & 13,04 & 13,14 & 13,39 \\
Heritiera sp. & 13,41 & 13,21 & 13,24 & 13,45 \\
\hline
\end{tabular}

Table 2. Density of wood before and after preservative treatment using carbon dioxide impregnation

\begin{tabular}{lcccc}
\hline \multirow{2}{*}{ Wood species } & \multicolumn{4}{c}{ Wood density $\left(\mathrm{g} / \mathrm{cm}^{3}\right)$} \\
\cline { 2 - 5 } & Before treatment & \multicolumn{3}{c}{ After treatment } \\
\cline { 2 - 5 } & & 10 min. & 20 min. & 30 min. \\
\hline Agathis sp. & 0,49 & 0,51 & 0,52 & 0,51 \\
Palaquium sp. & 0,42 & 0,47 & 0,45 & 0,45 \\
Heritiera sp. & 0,62 & 0,59 & 0,60 & 0,59 \\
\hline
\end{tabular}


Table 3. Tangential shrinkage and swelling of wood before and after preservative treatment using carbon dioxide impregnation

\begin{tabular}{|c|c|c|c|c|c|c|c|c|}
\hline \multirow{4}{*}{ Wood species } & \multicolumn{8}{|c|}{ Tangential shrinkage (Sr) and swelling (Sw) of wood } \\
\hline & \multirow{2}{*}{\multicolumn{2}{|c|}{ Before treatment }} & \multicolumn{6}{|c|}{ After treatment } \\
\hline & & & \multicolumn{2}{|c|}{$10 \mathrm{~min}}$. & \multicolumn{2}{|c|}{$20 \mathrm{~min}}$. & \multicolumn{2}{|c|}{$30 \mathrm{~min}}$. \\
\hline & $\operatorname{Sr}(\%)$ & Sw $(\%)$ & $\operatorname{Sr}(\%)$ & Sw (\%) & $\operatorname{Sr}(\%)$ & Sw $(\%)$ & $\operatorname{Sr}(\%)$ & Sw (\%) \\
\hline Agathis sp. & 3,09 & 3,28 & 3,62 & 2,69 & 3,69 & 3,23 & 3,74 & 3,33 \\
\hline Palaquium sp. & 2,84 & 3,09 & 3,10 & 3,00 & 3,33 & 3,03 & 3,06 & 2,85 \\
\hline Heritiera sp. & 3,64 & 3,14 & 3,47 & 3,42 & 3,64 & 3,45 & 4,03 & 3,66 \\
\hline
\end{tabular}

\section{Penyusutan dan Pengembangan}

\section{Penyusutan dan Pengembangan Tangensial}

Hasil pengamatan terhadap persentase penyusutan dan pengembangan tangensial pada jenis kayu agathis, kayu nyatoh, kayu palapi yang melalui proses pengawetan dan tanpa melalui proses pengawetan menunjukkan bahwa kayu palapi memiliki rata-rata persentase penyusutan dan pengembangan tangensial lebih besar dari kayu agathis dan kayu nyatoh masing-masing sebesar $3,70 \%$ dan $3,42 \%$ sedangkan kayu agathis masing-masing sebesar $3,54 \%$ dan $3,13 \%$ dan kayu nyatoh masing-masing sebesar $3,08 \%$ dan $2,99 \%$. Hasil analisis ragam menunjukkan bahwa hanya faktor jenis kayu yang mempengaruhi penyusutan tangensial, sedang lama pengawetan serta interaksi keduanya tidak memberikan pengaruh yang nyata. Hasil uji BNJ menunjukkan bahwa penyusutan tangensial kayu palapi berbeda tidak nyata dengan kayu agathis tetapi berbeda nyata dengan kayu nyatoh. Sedangkan kayu agathis tidak menunjukkan perbedaan yang nyata dengan kayu nyatoh dan kayu palapi. Penyusutan dan pengembangan tangensial kayu agathis, nyatoh, dan palapi sebelum dan setelah mengalami proses pengawetan dapat dilihat pada Tabel 3.

\section{Penyusutan dan Pengembangan Radial}

Hasil pengamatan terhadap persentase penyusutan dan pengembangan radial pada jenis kayu agathis, kayu nyatoh, kayu palapi yang melalui proses pengawetan dan tanpa melalui proses pengawetan menunjukkan bahwa kayu palapi memiliki rata-rata persentase penyusutan dan pengembangan radial lebih besar dari kayu nyatoh dan kayu agathis. Kayu palapi menunjukkan nilai penyusutan dan pengembangan masing-masing sebesar 2,72\% dan 2,57 \%, sedangkan kayu agathis masingmasing sebesar $2.59 \%$ dan $2,43 \%$ dan kayu nyatoh masing-masing sebesar 2,11\% dan 2,09 $\%$. Hasil analisis ragam menunjukkan bahwa hanya faktor jenis kayu yang mempengaruhi penyusutan radial, sedang faktor lama pengawetan dan interaksi keduanya tidak memberikan pengaruh yang nyata. Hasil uji BNJ menunjukkan bahwa penyusutan radial kayu palapi berbeda tidak nyata dengan kayu agathis tetapi menunjukkan perbedaan yang nyata dengan kayu nyatoh. Penyusutan dan pengembangan radial kayu agathis, nyatoh, dan palapi sebelum dan setelah mengalami proses pengawetan dapat dilihat pada Tabel 4 .

\section{Nilai T/R Rasio}

Hasil perhitungan terhadap $T / R$ rasio pada jenis kayu agathis, kayu nyatoh, kayu palapi yang melalui proses pengawetan dan tanpa melalui proses pengawetan menunjukkan bahwa rata-rata T/R rasio kayu palapi $(1,34)$ lebih kecil dari kayu agathis dan kayu nyatoh yang masing-masing

Table 4. Radial shrinkage and swelling of wood before and after preservative treatment using carbon dioxide impregnation

\begin{tabular}{|c|c|c|c|c|c|c|c|c|}
\hline \multirow{4}{*}{ Wood species } & \multicolumn{8}{|c|}{ Radial shrinkage (Sr) and swelling (Sw) of wood } \\
\hline & \multirow{2}{*}{\multicolumn{2}{|c|}{ Before treatment }} & \multicolumn{6}{|c|}{ After treatment } \\
\hline & & & \multicolumn{2}{|c|}{$10 \mathrm{~min}}$. & \multicolumn{2}{|c|}{20 min. } & \multicolumn{2}{|c|}{$30 \mathrm{~min}}$. \\
\hline & $\operatorname{Sr}(\%)$ & Sw $(\%)$ & $\operatorname{Sr}(\%)$ & Sw $(\%)$ & $\operatorname{Sr}(\%)$ & Sw $(\%)$ & $\operatorname{Sr}(\%)$ & Sw (\%) \\
\hline Agathis sp. & 2,19 & 2,59 & 2,94 & 2,24 & 2,39 & 1,84 & 2,84 & 3,05 \\
\hline Palaquium sp. & 2,11 & 1,86 & 2,28 & 2,01 & 2,07 & 2,64 & 2,01 & 1,90 \\
\hline Heritiera sp. & 2,67 & 2,53 & 2,48 & 2,37 & 2,93 & 2,78 & 2,76 & 2,59 \\
\hline
\end{tabular}


sebesar 1,59 dan 1,77. Hasil analisis ragam T/R rasio pada ketiga jenis kayu dengan berbagai perlakuan menunjukkan bahwa baik faktor lama pengawetan, jenis kayu dan interaksi keduanya tidak memberikan pengaruh yang nyata.

Secara keseluruhan, hasil-hasil penelitian seperti dikemukakan di atas menunjukkan bahwa perlakuan pengawetan dengan impregnasi menggunakan $\mathrm{CO}_{2}$, termasuk lamanya proses berlangsung pada kisaran sampai dengan 30 menit, tidak berpengaruh nyata terhadap sifat fisik dan stabilitas dimensi kayu. Hal ini menunjukkan tidak terjadinya interaksi kimia yang bersifat negatif dari penggunaan $\mathrm{CO}_{2}$ sebagai pelarut dengan kayu yang diawetkan. Hal ini sesuai dengan yang dikemukakan oleh Larsen et al..(1992) bahwa penggunaan $\mathrm{CO}_{2}$ tidak menyebabkan interaksi kimia yang merusak dinding sel kayu yang diawetkan. Di samping itu, penggunaan $\mathrm{CO}_{2}$ terbukti tidak menyebabkan interaksi kimia yang bersifat negatif terhadap komponen dinding sel kayu, tetapi interaksi fisik dan mekanis dapat terjadi sebagai akibat perubahan tekanan dan/atau suhu perlakuan (Muin et al., 2001; Muin and Tsunoda, 2003).

\section{KESIMPULAN}

Pengawetan dengan menggunakan karbondioksida sebagai pelarut pembawa tidak mempengaruhi sifat fisik kayu (kadar air, kerapatan, penyusutan dan pengembangan serta $T / R$ rasio). Adanya retak dan pecah pada kayu nyatoh sebagai akibat pengawetan menggunakan karbondioksida sebagai pelarut pembawa perlu mendapat perhatian dengan memperhatikan faktor-faktor atau parameter proses untuk mencegah terjadinya retak atau pecah pada kayu yang diawetkan. Dalam hal ini, perlu dilakukan modifikasi laju pemberian tekanan dalam proses pengawetan kayu-kayu yang memiliki permeabilitas rendah.

Diterima : 12 Oktober 2006

Ifa Zanty Wahyuni, Musrizal Muin, dan Suhasman Lab. Keteknikan dan Diversifikasi Produk Hasil Hutan Jurusan Kehutanan, Universitas Hasanuddin Kampus Tamalanrea, Jl. Perintis Kemerdekaan Km. 10, Makassar 90245 Telp./Fax. 0411-585917. Indonesia

\section{Natsir Usman}

Balai Besar Industri Hasil Hutan Jl. Racing Centre No. 28, Makassar

\section{DAFTAR PUSTAKA}

Gaspersz, V. 1991. Metode Perancangan Percobaan. Penerbit CV. Armico, Bandung.

Hunt, G.M. dan Garratt, G.A. 1953. Wood Preservation. McGraw-Hill Book Company, Inc. New York.

Larsen, A., N.A. Jentoft and T. Geibokk. 1992. Extraction of Formaldehyde from Particelboard with Supercritical Carbon Dioxide. Journal of Forest Products, Vol. 42 No. 4: 45-48.

Martawijaya, A., I. Kartasujana, K. Kadir, S.A. Prawira, 1981. Atlas kayu Indonesia: Jilid I. Pusat Penelitian dan Pengembangan Kehutanan. Bogor.

Minamite, Y., T. Kanzaki and Y. Katsuda. 1990. Application of a Novel Silaneophane (Hoe498) to Termicides. Japan Journal of Enviromental Entomology and Zoology. Vol. 2: $117-122$.

Muin, M., A. Adachi, dan K. Tsunoda. 2001. Applicability of supercritical carbon dioxide to the preservative treatment of wood-based composites. The International Research Group on Wood Preservation, Document No. IRG/WP 01-40199.

Muin, M. and K. Tsunoda. 2003. Preservative Treatment of Wood-Based Composites with 3lodo-Propynyl Butylcarbamate Using Supercritical Carbon Dioxide Impregnation. Journal of Wood Science 49: 430-436

2004. Biological Performance of Wood-Based Composites Treated with a Formulation of of 3-lodo-2Propynyl Butylcarbamate and Silafluofen Using Supercritical $\mathrm{CO}_{2}$. Journal of Wood Science 50: 535-539. 